\title{
Cylindrical Block Co-Micelles With Spatially Selective Functionalization by Nanoparticles
}

\author{
Hai Wang, ${ }^{\dagger}$ Wanjuan Lin, ${ }^{\dagger}$ Karolina P. Fritz, 'Gregory D. Scholes, ${ }^{\dagger}$ Mitchell A. Winnik, ," and \\ Ian Manners, \\ 'Department of Chemistry, University of Toronto, 80 St. George Street, Toronto, Ontario M5S 3H6, \\ Canada \\ ${ }^{*}$ School of Chemistry, University of Bristol, Bristol BS8 ITS, United Kingdom \\ mwinnik@chem.utoronto.ca; Ian.Manners@bristol.ac.uk
}

\section{Supporting Information:}

\section{Synthesis of Quaternized PFS-P2VP Cylindrical Micelles (2)}

The synthesis of PFS-P2VP (structure shown below) block copolymers was reported previously using a 1,1-dimethylsilacyclobutane (DMSB) mediated sequential anionic polymerization." The " $x$ " in the structure represents the number of DMSB units incorporated in the polymer chains. Since this number is so small that it is very difficult to determine precisely, we denote " $x$ " in the formula. On average, this number should be no more than 2 as we added two equivalents of DMSB related to the PFS living chains into the reaction mixture with the presence of 1,1-diphenylethylene. $\mathrm{PFS}_{17}-\mathrm{P}_{2} \mathrm{VP}_{170}$ cylindrical micelles (1) were prepared by mixing $\mathrm{PFS}_{17}-\mathrm{P} 2 \mathrm{VP}_{170}$ with isopropanol at room temperature with stirring for 1 hour. To the micelle solution $(5.0 \mathrm{mg} / 10 \mathrm{~mL}$, pyridyl group content: $\left.3.9 \times 10^{-2} \mathrm{mmol}\right)$ ) was added MeI $\left(24 \mu \mathrm{L}, 3.9 \times 10^{-1} \mathrm{mmol}\right)$ at room temperature with stirring. After $24 \mathrm{~h}$, hexanes was added to precipitate the micelles. The product micelles (2) were isolated and further purified by dissolution in isopropanol followed by precipitation and washing with hexanes. This cycle was repeated three more times and the isolated solid consisting of $\mathbf{2}$ was dried under vacuum overnight.

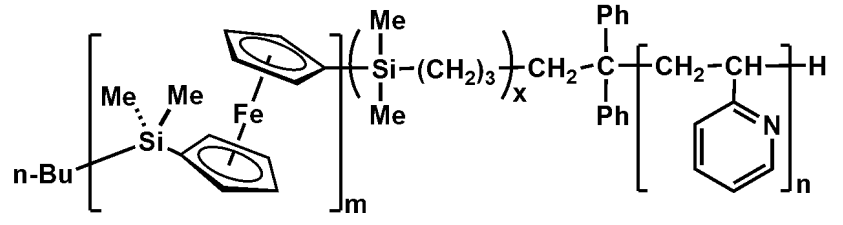

PFS-P2VP

\section{Synthesis of Block Co-Micelles (3)}

Shortened, seed micelles were prepared from quaternized PFS-P2VP cylinders (2) by placing the sample in a 60 watt ultrasonic cleaning bath at room temperature for $3 \mathrm{~min}$. To a $1 \mathrm{~mL}$ aliquot of this micelle solution $(0.5 \mathrm{mg} / \mathrm{mL})$ a $100 \mu \mathrm{L}$ THF solution of PFS $_{17^{-}}$ 
P2VP $170(10 \mathrm{mg} / \mathrm{mL})$ was added. After $24 \mathrm{~h}$, the sample (3) was used for further experiments.

\section{Synthesis of PbS Nanocrystals}

$\mathrm{PbS}$ NCs were synthesized using the procedure previously reported. ${ }^{2,3}$ Lead oleate precursors were prepared by heating $\mathrm{PbO}$ in oleic acid $(\mathrm{OA})$ at concentrations from $0.1-$ $0.5 \mathrm{M}$ under argon at $150{ }^{\circ} \mathrm{C}$. Bis(trimethylsilyl)sulfide (TMS) solution in 1-octadecene (ODE) was rapidly injected into a 3-neck flask containing the lead oleate precursor at a temperature in the range from $50{ }^{\circ} \mathrm{C}-150{ }^{\circ} \mathrm{C}$ (depending on the desired size of nanocrystal being prepared). After growth, the PbS NCs were isolated by precipitation using ethyl acetate. They were subsequently redispersed into toluene.

\section{Selective Functionalization of Block Co-Micelles With Au and PbS Nanoparticles (4)}

$\mathrm{Au}$ nanoparticles were synthesized following a slightly modified literature procedure. ${ }^{4,5}$ We used mercaptoacetic acid instead of 11-mercaptoundecanoic acid as the stabilizing agent. Dissolution of Au NPs in deionized water and the addition of an aqueous solution of $\mathrm{Me}_{4} \mathrm{~N}^{+}[\mathrm{OH}]^{-}$gave a deep purple solution of Au NPs $(5 \mathrm{mM})$ with $\mathrm{pH}$ $\sim 8$.

To a $100 \mu \mathrm{L}$ solution of micelles 3 in isopropanol was added deionized water (100 $\mu \mathrm{L})$. The resulting solution was clear and free of precipitation. Addition of a $40 \mu \mathrm{L}$ aqueous solution of Au NPs led to a light purple solution of the micelle-Au nanoparticle composite (4). Functionalization of micelles 3 with poly(acrylic acid) stabilized $\mathrm{PbS}$ quantum dots was carried out in a similar manner.

(1) Wang, H.; Winnik, M. A.; Manners, I. Macromolecules 2007, 40, 3784.

(2) Hines, M. A.; Scholes, G. D. Adv. Mater. 2003, 15, 1844.

(3) Fritz, K. P. Applications of Size \& Shape Dependent Properties of Nanocrystalline $\mathrm{PbS}$ and CdSe. Ph.D. Thesis, University of Toronto, 2007.

(4) Jana, N. R.; Peng, X. G. J. Am. Chem. Soc. 2003, 125, 14280.

(5) Kalsin, A. M.; Fialkowski, M.; Paszewski, M.; Smoukov, S. K.; Bishop, K. J. M.; Grzybowski, B. A. Science 2006, 312, 420. 